\title{
10 health stories that mattered: Dec. 2-6
}

- Reports of US border services accessing the private health information of Canadians will be investigated by Ontario Information and Privacy Commissioner Ann Cavoukian. Questions were raised after an Ontario woman went public about being refused entry to the United States after a border agent discovered she had once had a mental illness episode.

- There is "no healthy pattern" of obesity, researchers in Toronto, Ontario, concluded in a new meta-analysis. A review of eight studies involving more than 61000 people indicated that obesity increases long-term health risks "even in the absence of metabolic abnormalities." This is strong evidence that "healthy obesity" is a myth, stated an accompanying editorial.

- A social media campaign to promote organ and tissue donation was launched by federal Health Minister Rona Ambrose. There are more than 4500 Canadians waiting for organ donations, noted Ambrose. The government has created a webpage to assist Canadians in registering as donors.

- Delaying the introduction of "trigger" foods such as peanuts, eggs or fish to the diets of high-risk infants beyond six months does not prevent food allergies, the Canadian Paediatric Society said in a position statement. The statement notes, however, that "inducing tolerance by introducing solid foods at four to six months of age is currently under investigation and cannot be recommended at this time."

- A Nova Scotia shop has been asked by Health Canada to stop selling electronic cigarettes, reports the CBC. Electronic smoking products "pose risks such as nicotine poisoning and addition" and selling them is "not compliant with the Food and Drugs Act," Health Canada wrote in a letter.

- Dr. Gordon Guyatt received the title of Canada's Health Researcher of the Year from the Canadian Institutes of Health Research. Guyatt, a professor in the Department of Clinical Epidemiology and Biostatistics at McMaster University in Hamilton, Ontario, was an early champion of the concept of evidence-based medicine.

- The Ontario government again came under fire over the millions paid to the former CEO of the scandalplagued Ornge air ambulance services. Dr. Chris Mazza, who was fired in 2012, received nearly $\$ 10$ million over six years.

- A fertility clinic in British Columbia is permitted to destroy sperm and embryo samples if clients don't indicate by Dec. 24 that they want the samples transferred, decided the province's Supreme Court. More than 1200 people have samples stored at the clinic, which stopped operating last year.

- Only 1 of 99 Alberta Health Services executives chose not to accept a performance bonus, even though Health Minister Fred Horne requested they not take the money. In total, the "payat-risk" payments, which are linked to meeting performance targets, came to about $\$ 3$ million.

- Millions of upper lip hairs, ranging in length from short to less-short, fell victim to razors with the end of Movember, a charity in support of men's health. Though there have been several reports of chilly philtrums, they have received little attention amid the ecstatic cries of moustache-averse spouses. So far, \$28 million has been raised in Canada this year by the charity. Roger Collier, CMAJ

CMAJ 2014. DOI:10.1503/cmaj.109-4678 